\title{
Assortment Portfolio Price Positioning of a Transnational Corporation in the Ukrainian Market
}

\author{
Serhii Smerichevskyi ${ }^{1 *}$, Tetiana Kniazieva $^{1}$, Svitlana Smerichevska ${ }^{2}$, \\ Anna Shevchenko ${ }^{1}$ \\ ${ }^{1}$ Marketing Department, National Aviation University, Ukraine \\ ${ }^{2}$ Logistics Department, National Aviation University, Ukraine
}

\begin{abstract}
The paper deals with the critical stages of the evolution of theoretical approaches to the positioning strategies content. On this basis, the key approaches to the market positioning processes management formulated. The correlation between the concept of creating consumer value and the price positioning strategy proved. The algorithm of the process of forming and implementing the strategy of assortment portfolio price positioning of a transnational corporation on the Ukrainian market proposed.
\end{abstract}

\section{Introduction.}

The development of management strategies under different market conditions and the choice of optimal positioning methods, including a wide range of producing products price positions, is an essential and complicated task for the companies' management under current unstable market conditions, with a decrease in people's consumer activity. The search for sound management decisions is complicated due to many factors of the internal and external environment and requires a fully justified algorithm of actions. The management process is a whole series of interconnected analytical procedures and decisions that allow the company to move consistently towards achieving its intended strategic goal. These procedures and decisions are also typical for the process of price positioning formation, the importance of which is exceptionally high, given the fact that the price as a monetary category concentrates the expectations of financial results on which the company focused. In this respect, pricing becomes the basis of all other product management decisions.

In current conditions, when economic instability contributes to the growth of the price sensitivity of people and reducing their consumer activity, transnational corporations are facing another round of crisis behaviour in most categories of convenience goods. The need for the systematic development of management concepts and methods in this area is determined by the relevance of the topic of this article.

In foreign and domestic scientific literature, some problems of price positioning of transnational corporations considered many authors [1-10]. In these works, the definitions of the key concepts of strategic management that form the basis of the positioning concept are

\footnotetext{
*Corresponding author: s_f_smerichevsky@ukr.net
} 
given: 1) positioning related to the long-term strategy of the company since it takes time to create the desired position; 2) positioning occurring in the minds of consumers; 3) positioning based on obtaining the benefit; 4) the product's position in the mind of one buyer may differ from the same product's position in the mind of another buyer. Therefore, it is crucial to understand the position the product occupies in the minds of consumers of all market segments which are essential for a company; 5) positioning is a relative concept in a competitive market environment because the products occupy the positions relative to competing ones. Positioning is an essential means of ensuring the competitiveness of national and international companies.

Despite numerous works in the field of market strategies development, most of them leave rather unaddressed issues related to the development and implementation of product portfolio management strategies of the company. The factors arising within the product portfolio and directly influencing the development of the positioning strategy for the company's aggregative portfolio are not sufficiently studied. Many companies do not control positioning in distribution channels, which leads to significant problems in the perception of the companies' products and financial losses. A real challenge for any company operating on the consumer market is to turn the pricing process into a strategic management competence within the company.

The objective of the article is theoretical justification and development of a management algorithm of forming the strategy of a broad assortment portfolio price positioning based on systematisation the transnational corporations' strategic management in the Ukrainian market.

\section{The genesis of the approaches to the market positioning strategies development.}

The market strategy of a company is a complex, multi-aspect category. It should set a specific direction of development and coordinate the efforts within the company on its basis to achieve the desired position in the future, reflect the nature of the organisation and demonstrate its distinctive features, as well as contain a set of rules that will guide the company in making a management decision. The market strategy is designed to provide sustainable competitive advantages in the present and in the medium-term perspective to achieve the desired strategic position of the company in the future.

In current market conditions, the statement that two key factors determine the choice of competitive strategy of the company remains relevant: the profitability of the industry and the positioning of the company within one or another industry $[3,5]$. Depending on the company's positioning relative to other market participants, its revenues will be higher or lower than the average level in the industry. These competitive advantages, combined with the competitive environment of the market segment in which the company seeks to achieve the desired position, form the key management parameters and allow developing types of competitive strategies: leadership in minimising costs, differentiation or focusing.

The management practice of transnational corporations (such as Coca-Cola, Samsung, Toyota, Nestle, Nokia, Metro Cash\&Carry, Hewlett-Packard, British American Tobacco, etc.) shows the features of its application:

1) when developing a strategy of the market segment, the company's management uses specific attributes that meet the identified customers' needs and position products or brands uniquely;

2) the differentiation of goods or brands is based on the unique properties of the product itself, the peculiarities of implementation or particular marketing approach in the field of merchandising and product placement within retail facilities; 
3) several companies in the Ukrainian consumer market at the same time successfully implement the strategy of differentiation;

4) several parameters appreciated by buyers characterise products and brands in the consumer market;

5) key market players seek to bring their costs closer to their target competitors by managing costs, reducing costs in areas that are not directly related to the chosen direction of differentiation;

6) companies' management invests significant financial and human resources in support and development of market expertise, analysis and forecasting of market trends, the so-called macro trends, as well as in the technologies development.

Within the globalising process of the transnational corporations brand portfolio, it is also necessary to decide which brands have the potential to become global and which will remain national trademarks.

The study of the evolution of the theoretical views within the positioning concept allows comprehending the changes which occurred over the past few decades and transformed strategic management into its current state, analysing the accumulated the theory and practical application of fundamental theoretical approaches in the positioning strategy development. Based on the analysis of the formation and development of the positioning concept, it is possible to distinguish four main stages of theoretical thought evolution within the price positioning concept.

It can be said that the conceptual framework of strategic positioning (the first stage of the theoretical thought development) are presented in the works of John Francis Trout and Al Ries [9]. The key idea of the positioning concept is that positioning is the management of the consumer's opinion about the position of a particular product among many other brands of a given or related product group. The positioning aims to create such an impression among consumers that they see a unique, one-of-a-kind product for which there is no equivalent replacement. At the same time, the position of a brand in the consumer's mind is a relative concept since based on the consumer's comparative assessment of this product with competing analogues. Strategic positioning is the result of related management decisions, which create a set of ideas about the product. The main types of characteristics used by the company's management to develop a positioning strategy are product properties; advantages, problem-solving and essential needs; price and quality; features of use; product consumer.

At the second stage of the positioning concept evolution, theorists and practitioners of strategic management developed methodical management approaches to the effective positioning strategy formation and described the key stages of the strategic positioning process. For example, Jean-Jacques Lambin systematised quantitative methods used to develop an active positioning strategy, methods of assessing the current perception of products based on a multi-attribute product model.

At the third stage of the positioning concept evolution, key aspects are built in the framework of the brand management concept [1, 4]. Unlike John Francis Trout, representatives of this stage focus on emotional benefits as one of the most powerful bases for product differentiation, and within this direction, the key components of brand positioning, such as identity elements, value proposition, brand-communications, and advantages highlighted and developed. The concept of portfolio approach was also introduced, which is extremely important for modern management, because, in this approach, manufactured goods are not considered separately from each other, but as an interconnected aggregation of brands, therefore, for maximising brand portfolio effective management, a clear understanding of the roles of each of them in the portfolio is needed.

The fourth stage of the management approaches to the positioning concept evolution is interesting because it focuses on the interrelated managerial stages of the company's actions in creating and launching products into the market. Within this direction, the following most 
well-known models should be mentioned: 4D branding (a model, which includes functional, social, mental and spiritual aspects), Bates Worldwide Brand Wheel model (the model allows consistently linking the brand's essence with goods or services specific properties), the Thompson Total Branding model, the Brand Key model of Unilever, the Brand Platform model of Young \& Rubicam, the Censydiam System of the Synovate company, the Brand Pyramid model of Mars and others. Within these models' framework, the positioning strategy management based on various key aspects that are most important for creating and launching products onto the market in multiple industries and competition conditions.

Analysis of various theories shows that the development directed to the understanding of multiple technologies of the positioning processes management. A systemic analysis of the positioning concept transformation leads to understanding that creating customer value is the key result of the positioning strategy.

\section{The algorithm of a process of price positioning development and implementation in strategic management of a transnational corporation.}

The consumer value concept focuses on the satisfaction of basic needs and involves the process of creating values that are difficult to copy for a transnational corporation's competitors. Having analysed the modern development of conceptual approaches to the process of value production management, it can be concluded that the scheme of the central management relationships between the market segment strategy and the positioning strategy should be supplemented by management blocks of controlling the positioning strategy implementation, and monitoring the chain of creation and proposition of value to the target market segment [10]. It is this algorithm of management decisions that should be the basis for the management of positioning processes.

The role of price as a significant attribute of the product for the consumer is typical for many consumer markets. On this basis, companies sometimes build the entire strategy of the product or brand positioning on the price. Thus, from the management position, it is necessary to run not a technical analysis, but the analysis of quality and price perception.

It is important to note several characteristics of the price as the market strategy element [2, 6-8]: 1) the price affects the level of demand and determines the level of buyers' activity depending on the sensitivity to the price; 2) the price directly affects the profitability of the company's commercial activity and the achievement of the company's operational goals (quantitative terms of the company's strategic goals); 3) the price has a direct effect on the overall product or brand perception and is one of the essential factors determining the positioning for the target audience; 4) the price, unlike other product attributes, allows a direct comparison of competing goods; 5) the price must comply with other elements of the company's market strategy, particularly taking into account the distribution strategy and providing the necessary trade margin.

Thus, price positioning is the most critical element of the product positioning strategy and should aim at strengthening the proposition of consumer value. Based on the analysis of the relationship between the basic positioning strategy and the price strategy, it is possible to formulate an algorithm for the price positioning developing process and the pricing strategy (Fig. 1) and describe the critical stages of the process.

The stage of the positioning strategy implementation and delivering value to the target segment is critical to minimise the differences between the conceived strategy and the implemented one but does not guarantee its full implementation.

On the basis of this algorithm, the pricing strategy can be determine das a reasonable choice of several price options aimed at achieving the maximum (normative) profit for a 
transnational corporation on the market within the planned period, and to analyse three possible directions in the pricing strategy development: 1) cost-oriented pricing solutions (methods and strategies), 2) demand-oriented pricing solutions, 3) competition-oriented pricing solutions. From this statement, to conclude that demand-oriented pricing strategies are the most characteristic of the daily demand products categories.

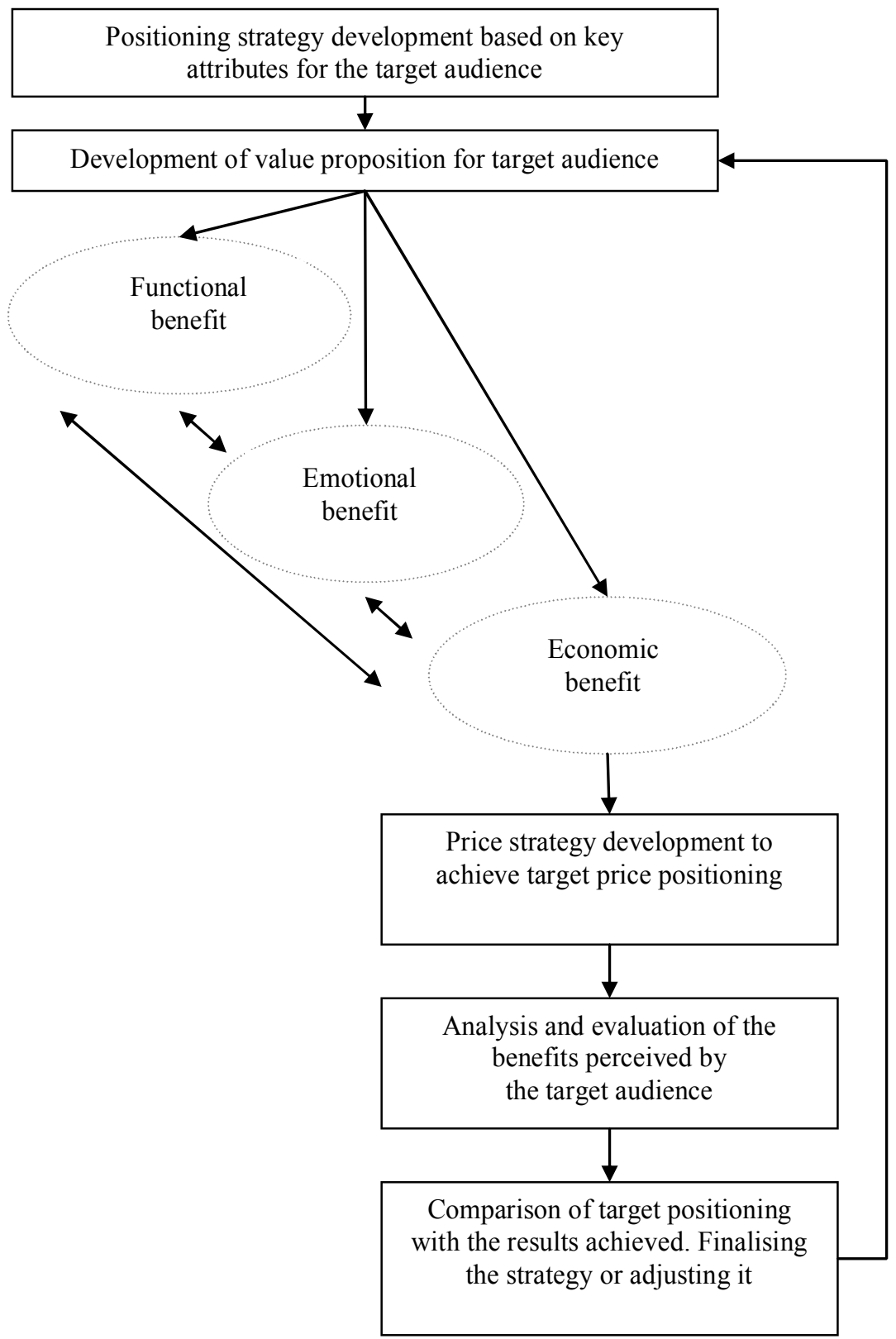

Fig. 1. The algorithm of price positioning development and implementation in strategic management of a transnational corporation

Thus, the paper specifies the vital management principle concerning the current market situation: the strategy is not static and can be subject to corrective changes, both at the stage 
of its implementation and at the monitoring stage to strengthen the brand's position on the market. Besides, it is necessary to keep in mind that the presence of significant pricing factors differences in the international activity of a company stimulates management to adapt not only the pricing strategy but also the brand positioning strategy.

The conducted research confirmed that the scheme of management of logical relationships between the market segment strategy and the price positioning strategy, proposed in the paper, should include blocks for monitoring the positioning strategy implementation, and monitoring the chain of creating and offering value for the target market segment. This approach should be the basis of the company's management algorithm. In this algorithm, it is necessary to pay special attention to the price positioning strategy implementation in key distribution channels. The lack of an adequate level of control can damage the identity of the forming brand. It is also important to predict the key competitors' potential reaction and to develop a plan in advance for maintaining and strengthening the critical brand's positions in a changing competitive environment.

\section{Conclusions.}

The determined necessity of transition from a traditional organisation and management models of a company to more complex models with enhanced external company's orientation, which require a quick management response within the company to the company's external environment changes at the structure, systems, and business processes levels. The systematisation of theoretical approaches to positioning as a method of strategic management is presented, which showed the current key factors and strategies of market positioning. Four stages of the positioning theory evolution are identified: the first stage - highlighting the positioning as a functional management area, the second stage - developing key elements of positioning, the third stage - the positioning concept transformation within the brand management, the fourth stage - developing a range of differentiated positioning models.

In the context of the relationship between consumer value and price positioning, the logical chain of management relations and management decisions is built, which should accompany the development of the element-functional strategy of a company.

It is proved in the paper that demand-oriented pricing strategies are the most typical for the transnational corporations' activities on the Ukrainian market in the daily demand goods categories, which allowed substantiating the most effective management method - the valueoriented method of positioning development. The management algorithm of forming and implementing the strategy of a company's assortment portfolio price positioning on the consumer market developed and the corrective measures proposed of positioning strategy management under the features of price-forming factors on the regional markets: 1) to improve distribution and representation in retail facilities: increasing a new product's quantitative distribution in key regional cities and implementing the MSL (Must Selling List) tool for key channels of modern retail to increase the average number of items; developing key principles of the critical brand categories placement in a retail facility within the relevant categories and close to key players in the category; 2) to run an additional product test to quantify the key product characteristics of the brand in the category; 3) to provide sales promotion: developing a promotional calendar of activities for the calendar year.

\section{References}


1. Becker-Ritterspach, F., Lange, K., \& Becker-Ritterspach, J. Critical perspectives on international business, 13(3), 186-203 (2017). https://doi. org/10.1108/cpoib-06-2016-0024.

2. Blajut, L. P. SEA - Practical Application of Science, 1(7), 97-102 (2015)...

3. Calabrese, A. International Journal of Production Economics, 135, 800-812 (2012)..

4. Ganushchak-Efimenko, L., Shcherbak, V., Nifatova, O., Kolodiziev, O. \& Rębilas, R. Innovative Marketing, 15(2), 14-29 (2019).. doi:10.21511/im.15(2).2019.02.

5. lazzolino, G. \& Migliano, G. Investment Management and Financial Innovations, 13(4), 106-119 (2016).. doi:10.21511/imfi.13(4).2016.09.

6. Kandrashina, E. A. \& Zotova, A. S. Problems and Perspectives in Management, 16(1), 437-444 (2018).. doi:10.21511/ppm.16(1).2018.41.

7. Melnychenko, R., Pugachevska, K., \& Kasianok, K. Investment Management and Financial Innovations, 14(4), $40-49$ (2017).. doi:10.21511/imfi.14(4).2017.05.

8. Romaniuk, M. Transfer pricing in the tax system of Ukraine. Proceedings of the International Economic Conference on World Trends and Prospects for the Development of the Financial System of Ukraine. Taras Shevchenko Kyiv National University, Kyiv, Ukraine. (2013).

9. Trout, J. \& Ries, A. (1981) Positioning: The Battle for Your Mind. New York: McGraw-Hill Education.

10. Wolff, M. Problems and perspectives in management, 5(2), 66-74 (2007). 